INTERNATIONAL JOURNAL OF ADVANCED ENGINEERING

AND BUSINESS SCIENCES (IJAEBS)

Journal homepage: International Journal of Advanced Engineering and Business Sciences (ekb.eg)

\title{
GIS Project Management
}

\author{
DR. ZAKARIA YEHIA AHMED
}

${ }^{a}$ Civil Engineering, Thebes Higher Institute of Engineering, Cairo, Egypt

\section{*Corresponding author: Email address: z.yehia@thebes.edu.eq}

\section{ABSTRACT}

GIS project managers are the people who manage a staff in geographic data analysis for a specific goal.

GIS project managers may become more integral and important to address the challenges of the projects. Project management like the knowledge application, skills, tools, and techniques to project activities in order to meet or exceed end user needs and expectations.

This paper describes definitions of GIS project management and specifies the resources and tools required. It ends with an overview of external factors and a discussion of the expertise required of a GIS project manager.

Key Words: Geographic Information Systems - Project departments - project management lifecycle (PMLC) - Characteristics of advanced GIS projects - Project Initiation - Project Planning - Project Execution - Monitoring and Control - Project Team - quality - stakeholder management - work breakdown structure (WBS).

\section{INTRODUCTION}

Project means a temporary administrative environment created for the purpose of producing one or more specific products according to specific specifications within a predefined time frame using predefined sources. There are many definitions of a project. Wysocki et al. (2003), one of them, define a project as "a sequence of unique, complex and connected activities having one goal or purpose that must be completed by a specific time, within budget, and according to specification" (p. 38). It is a logical sequence of activities that must be completed within a specific 
time frame. The Project Management Institute (PMI) (2013a, p. 8) defines project management "the application of knowledge, skills, tools, and techniques to project activities to meet the project requirement". This definition is added to five Project Management Process Groups (PMPG) that describe the lifecycle of any GIS project, and ten knowledge areas for the project managers should be competent.

The five PMPG are: Initiating processes, planning processes, executing processes, monitoring and controlling processes and Closing processes.

The ten knowledge areas, focus on management expertise in: project integration management, project scope management, time management, cost management, quality management, human resources management, communications management, risk management, procurement management and stakeholder management.

A successful project is one that meets stakeholder needs or exceeds stakeholder expectations.

Management means: GIS projects differ from traditional IS / IT projects. GIS projects are generally complex, expensive and have a spatial / geographical dimension. The field of geographic information systems is very broad and needs comprehensive management skill, which is often not acquired from university education centers, but is built through years of cumulative experience. There is very little experience available today in managing advanced GIS projects

Project Management: It is the application of knowledge, skills, means and techniques to a broad spectrum of activities in order to fulfill the specific requirements of that project to which this department is concerned. A project is an endeavor or a temporary path taken to reach a specific goal

\section{Geographic Information Systems “GIS":}

It has many definitions, one of which is: Geographic information systems: integrative systems that combine programs, devices, and qualified human competence, information and analytical methods to study spatial information - in its descriptive and geographic parts - associated with geodetic or global coordinates known in the globe's axes systems, and then monitor, store, recall, process, model, analyze, update, display, and distribute. The practical elements of project management are initiation, planning, executing, control and controlling, closing or locking. 


\subsection{Project departments:}

There are several project departments like project integration management, scope management, project time management, managing project budget and costs, project quality management, quality, resource human project, project communications department, risk management for the project, achievement management. procurement

\subsection{The most important advantages that will be achieved by the comprehensive geographic information system project:}

It provides a comprehensive information balance of data and geographical information (spatial and descriptive). Reducing costs of preparing and updating maps, data and geographical information and avoiding duplication of efforts and spending in this field. Provides an effective mechanism for transferring and exchanging geographical information vertically and horizontally and raising the level of utilization of information in this field.

Ease of obtaining information that supports the achievement of good planning for development projects. Provides information that enables coordination of population services and supports achieving justice in expanding the social services project.

Investors' access to extensive information services that enable them to use the geographic information system to study alternatives and make appropriate decisions regarding their investment activities.

\subsection{The main components of the geographic information system project:}

There are several components of the GIS project: an extensive database of spatial and descriptive information, provision of hardware, application software, preparation and qualification of cadres, system management and operation mechanisms

\subsection{Areas of geographic information systems projects:}

There are many GIS projects available in different fields today which help users to perform spatial queries and analysis (Security, Social services, Environment and tourism, Urban and urban development, Water, Government administration, Economic and commercial activities, Roads and transportation, Electricity, Human development and poverty alleviation programs, Communications, Land, wealth and natural resources, Etc.) 


\subsection{The project is studied from several aspects, namely:}

The nature of the different stages of the project

Data required to complete the project tasks (metadata - spatial data - satellite visuals)

Methods of obtaining the required data (survey - urbanization - mapping - available data questionnaires ... etc)

The work team required to complete the project tasks (surveyors - AutoCAD or GIS draftsmen - field survey team - data quality specialists - systems analysts - programmers ... etc.)

Equipment needed (Total Station - GPS Device ... etc)

Required software (AutoCAD - ARCGIS - Microsoft Office - ERDAS IMAGINE - Photoshop - ... etc)

The time required to achieve the project phases, each stage separately, according to the team and available equipment.

Finally, the expected cost and target financial return are calculated after providing all the project requirements

\subsection{The implementation of the work in stages according to the method of work:}

1- The analysis and design stage:

At this stage, a geographic information system is analyzed and an analysis report is produced for the system, which will contain the needs of users and assess the needs of the systems, applications and data required to be entered into them in preparation for their design.

2- The implementation phase and initial delivery:

Establishing a geographic information system database according to the specifications specified in the analysis and design stage.

3- Final handover stage:

Final delivery of the system, its supply and operation after implementing the required modifications.

Preparing and submitting the systems' user / help manual.

4- The training phase 


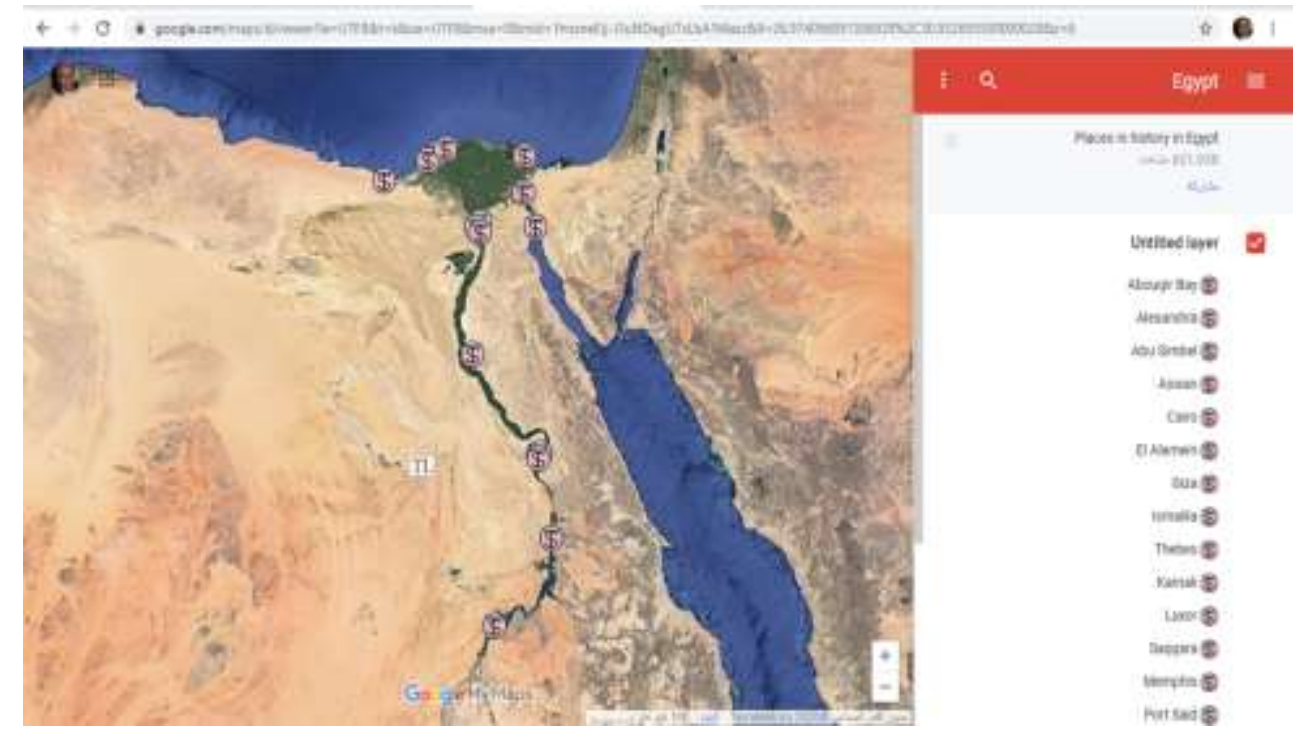

\subsection{The tasks that this department will deal with:}

\subsubsection{A number of tasks, but the most prominent of them are:}

1 - Preparing the specification brochure for the RFP GIS project and the documents related to the terms of reference ToR. This stage begins with the start of marketing for a project idea and ends with the selection of the best offers (awarding) to complete the project

2- Completion of the project.

This stage starts from the time of signing the contract with the implementing company and continues until the project is delivered and closed

3 - Project operation and investment

This stage starts from the time the project is received and its outputs accepted and continues along the length of the consideration the development, modernization and care of the life span of the various project elements

\subsection{Two types of management:}

\subsubsection{Strategic management}

It defines mission, vision, and value, and designs the broad lines through which a sector or facility will run. The rationale for the facility or sector is also created, and it defines the areas of marketing, the target customers or customers, as well as what the product is.

Strategic management must continue

\subsubsection{Project Management:}

It focuses on short-term results

The project must start and then finish 


\subsection{What is meant by "project initiation document"?:}

It should also include, as a minimum, the following elements:

Constrains determinants

Scope

Objectives \& Mission

Project Plan's Project Planner - Organization of the project

Outputs, timelines, output acceptance criteria and milestones, Deliverables

acceptance criteria.

Analysis Risk

\subsection{Characteristics of advanced GIS projects:}

Understanding user needs

This means that you interact as if you are a member of the user sectors and are aware of all their needs

Keep your balance

I mean, be neutral without giving preference to desires or specializations over others except to the extent of interest

Skill and craftsmanship in Geographic Information Systems "be a GIS professional"

It means providing the best of geographic information systems and its technologies so that the beneficiary sector can improve its performance, support its decisions, and feel the difference that geographical information systems make to its sector

\subsection{The keys to success:}

Good communication and understanding between all parties

Good coordination of resources

Adequate planning of resources

Good estimate of costs and duration

Good control and follow-up of project progress and progress

Existence of quality control mechanisms

Project deliverables should be scoped and defined-well

Resources allocated to the project must be available and assured

The structure and organization of the project must be sound and responsibilities are defined 


\subsection{The GIS project manager must know:}

Mission - Why are we doing this project?

Objective - what will be done?

Strategy - How can the project objectives be achieved?

\subsubsection{Key known reasons for failure of GIS projects:}

1 - Bad project planning

2 - Little or no support for the concerned administrative sector

3- Bad project management

4 - Lack of focus on user requirements and lack of active participation

\subsubsection{The biggest challenge for a project manager:}

Scope - Quality - Cost - Time

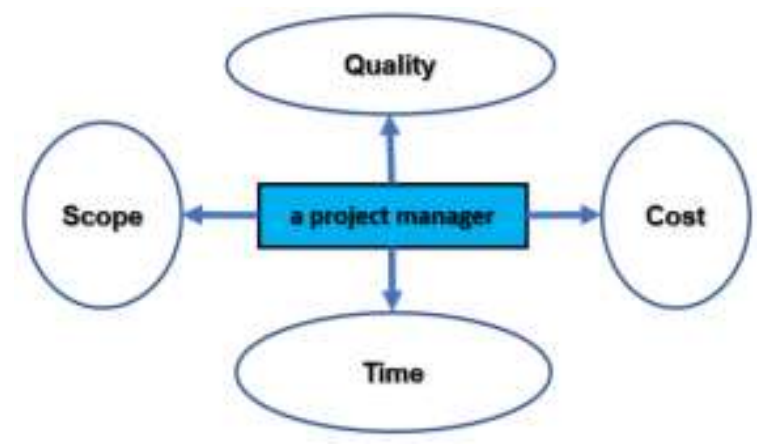

The project management Golden Triangle:

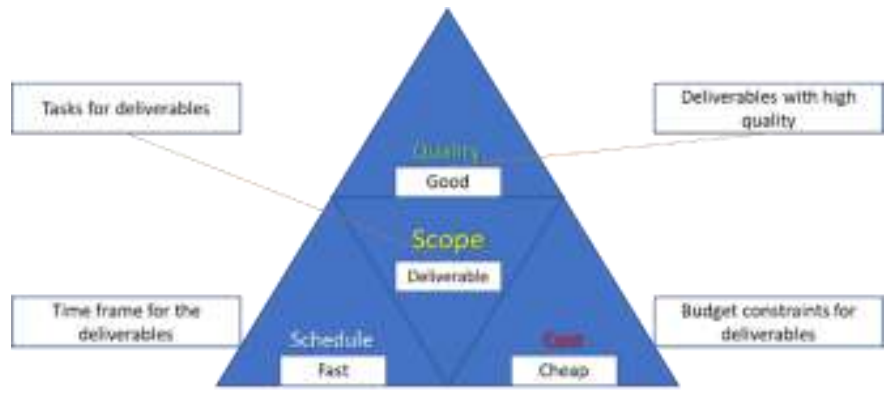

The Project Management 


\section{- Scope}

Scope is what we are going to produce and deliver at the end of the project as deliverables. It includes all the required features and functions that already defined and documented during the beginning of the project. Also, scope needs the supporting project efforts and functions required to oversee, organize and support the development of all deliverables.

\section{- Quality}

Quality is the minimum acceptable quality for the deliverables.

\section{- Schedule}

Estimate time for each task in the project. We need to ensure that we have the resources and time to finish the project.

\section{- Cost}

The project cost is a cost required to:

Procure all the needed products for the project.

Resources and Services to deliver the tasks of the project successfully.

\subsection{Project management lifecycle (five phases)}

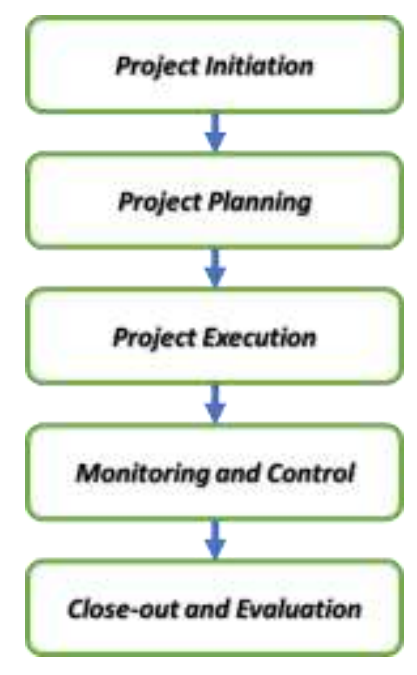

\subsection{Project Initiation:}

The start of the project is the first phase of the project management lifecycle and at this stage, companies decide whether the project is needed and how useful it is for them. The two criteria used to judge a proposed project and determine its expectations are the feasibility study and the business case. 
Project Initiation contains: identify problem / opportunity, establish the goal of the project, define objectives of the project, perform analysis of the cost/benefit, determine the criteria of success and assumptions list, obstacles list and risks list

\subsection{Project Planning}

Project Planning contains: identify activities of the project, estimate the requirements of the resource, construct the workflow and prepare the proposal of the project.

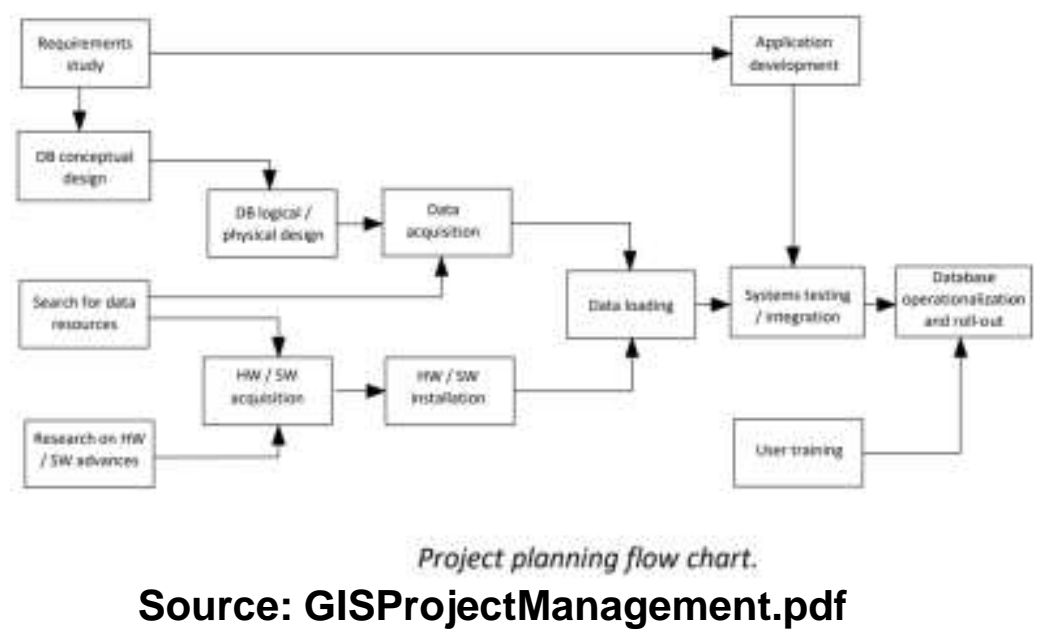

A project plan has 10 simple steps:

- Understand the value and scope of the project plan

- Conduct a thorough search

- Ask the hard questions

- Create your outline of project plan

- Talk to your team.

- Write down your entire project plan

- Do your plan in TeamGantt

- Publish the plan.

- Make sure read plan with your team

- Get ready to keep planning.

\subsection{Project Execution}

After we develop a project management plan and set the right baselines for the project, it's time to start working and start implementing the project plan. This is often the stage at which management becomes more interactive and enthusiastic to see things being produced.

Project Execution contains: organize the project team, establish the rules for the team, assemble resources of the project and execute project work plan 


\subsection{Monitoring and Control}

Monitoring and control keep projects on track. Correct controls can play a key role in completing projects on time. The data collected also allows project managers to make informed decisions. They can take advantage of opportunities, make changes and avoid crisis management problems.

Monitoring and Control contain: monitor the project progress with plan, establish protocol and procedures reports, install procedures of change management, establish mechanism of problem resolution and revise the project plan

\subsection{Close-out and Evaluation}

The project is closed at the end of the project life cycle (Project closeout). It's a coronation. Activities that start before the delivery of the facility, and end with the suspension of the capital in full financial activity to support the project. The closure process involves closing the final contracts and closing the project management office. Archive records and produce a project completion report. The project manager is the project is expected to be closed within three months after completion of warranty period (usually one year after substantial performance).

Close-out and Evaluation contain: conduct the acceptance test, establish roll out plan and schedule, complete documentation of project, conduct audit of post-implementation and Complete the final project report. 


\subsection{Project Team:}

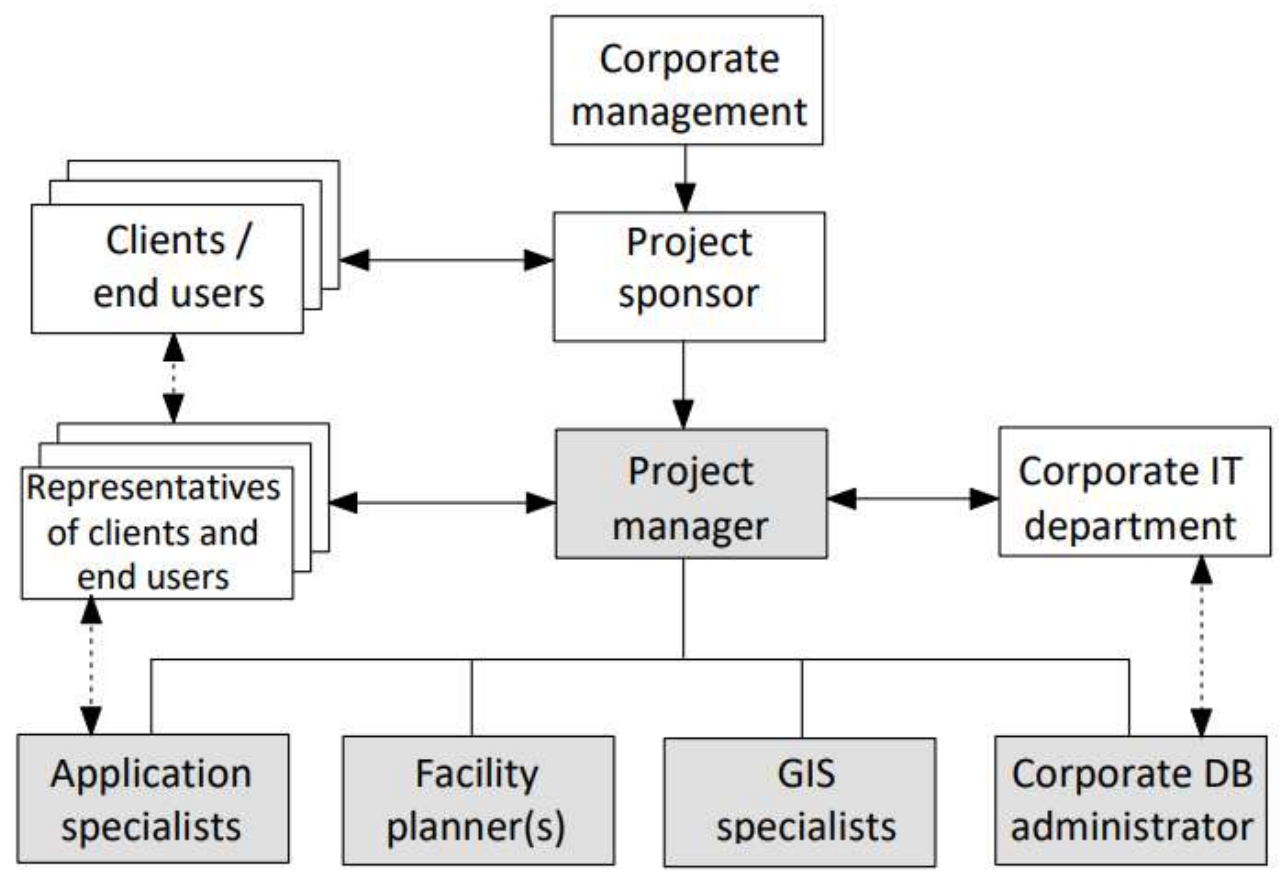

\section{Organigram of a GIS project and its setting in a larger organizational context. Source: GISProjectManagement.pdf}

\subsection{Stakeholder management}

The project manager can identify stakeholders early in the GIS project. For every stakeholder, he has to important to determine what they need and what influence or power they have. Based on this information, the need to communicate with them.

Increasing the number of stakeholders add pressure to the project and increase the complexity of the project. 


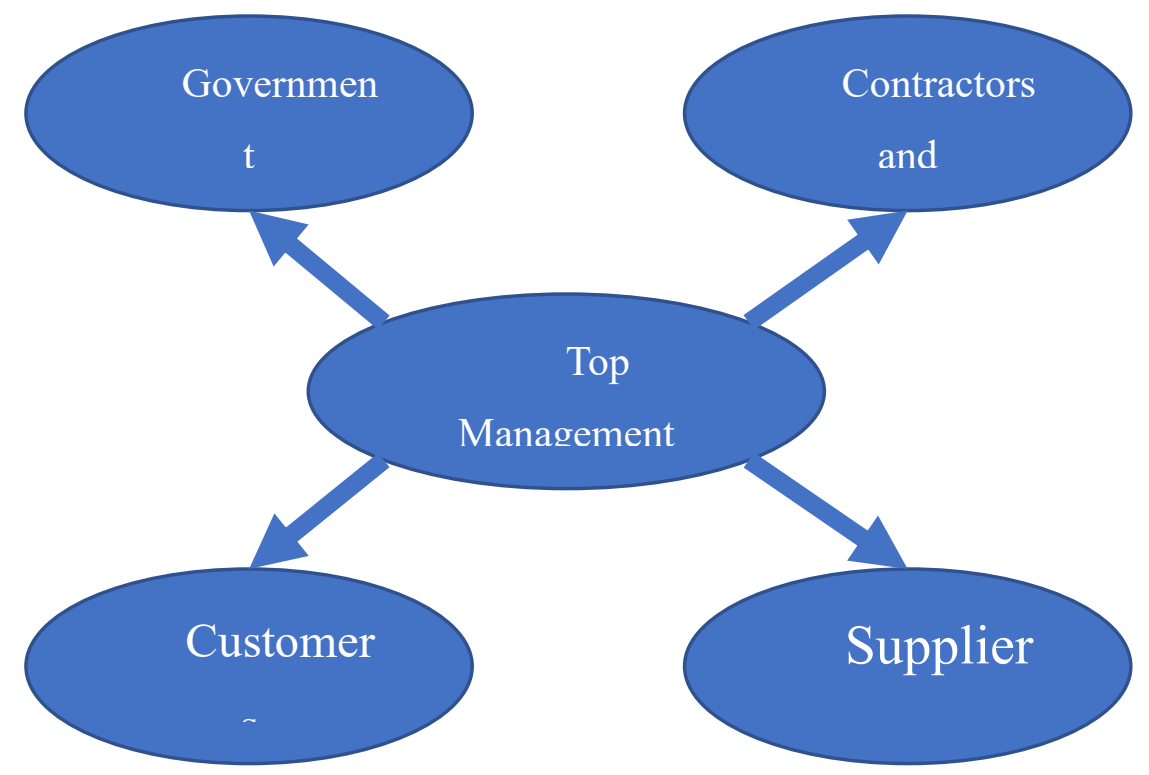

\section{Project}

\section{CONCLUSION:}

In GIS project management we need to look beyond the immediate application of GIS and see GIS implementations in a larger enterprise context.

A systematic investigation of what makes a GIS program successful requires analyzing and abstracting all the aspects of GIS project management discussed on the paper. This paper will hopefully put some insight on the complexities that experienced GIS managers have to learn to deal with. 


\section{LIST OF REFERENCES}

1. Barron, M and Barron, A. (2011) Project management for scientists and engineers. Galway, Ireland: Connexions

2. Burek, P. (2011). Influence of the scope statement on the WBS. Newtown Square, PA: Project Management Institute.

3. Chapman, A.D. (2005) Principles of data quality, Copenhagen, Denmark: Global biodiversity information facility.

4. Chrisman, N.R. (1983) "The role of quality information in the long-term functioning of GIS", Proceedings of AutoCarto 6, Vol. 2, pp. 305-321, Falls Church, VA: ASPRS.

5. Damodaran A (2007). Strategic Risk taking: a framework for risk management. Upper Saddle River, NJ: Prentice-Hall.

6. EPA (2003) Guidance for geospatial data quality assurance project plan, Washington, DC: Office of environmental information, US Environmental Protection Agency.

7. Harvey, F. (1997) "National cultural differences", in Theory and Practice. Information, Technology, and People. 10(2) 132-146.

8. Holton G. (2004) “Defining Risk”, Financial Analysts Journal, 60(6): 19-25.

9. Huxhold, W. (1996) Managing geographic information systems projects. New York: Oxford University Press.

10. Jakobs, R. (2017). Good business: Why placing ethics over profits pays off. Philips Blog, online resource, available at http://www.philips.com/aw/innovationmatters/blog/good-business-why-placing-ethicsover-profits-paysoff.html, last accessed 11/25/2016 .

11. Jochen Albrecht (2017) "GIS Project Management", City University of New York

12. Mulholland, N. (ed.) (2003) New York State project management guidebook, Albany, NY: New York State Office for Technology.

13. NETSSAF (2008). Proceedings, Network for the Development of Sustainable Approaches for Large Scale

14. Implementation of Sanitation in Africa Conference, 24 - 27 September 2008, Ouagadougou, Burkina

15. Faso. Online resource, available at http://www.ircwash.org/resources/netssafinternationalconference-pathways-towards-sustainable-sanitation-africa-24-27, last accessed 23 May, 2016.

16. Peters, P. (2008) Building a GIS. ESRI Press, Redlands, CA. 
17.Pressman, R. (2005) Software engineering: a practitioner's approach, 6th ed., New York, NY: McGraw Hall.

18. Project Management Institute (PMI) (2013a) Guide of the project management body of knowledge (commonly referred to as the PMBOK Guide), 5th ed., Newtown Square, PA: Project Management Institute.

19. Project Management Institute (PMI) (2013b). The standard for program management. Newtown Square, PA: Program Management Institute.

20. Project Management Institute (PMI) (2013c). The standard for portfolio management. Newtown Square, PA: Program Management Institute

21. Shi, Q., \& Chen, J. (2006). The human side of project management: leadership skills. Newtown Square, PA: Project Management Institute, Inc.

22. Standish Group (2016). The CHAOS report 2015. Boston.

23. Summerville, I. (2005) Software engineering, 7th ed., Boston, MA: Addison Wesley.

24. Thomas J. Cova (2018) "Comprehensive Geographic Information Systems", The University of Utah, Salt Lake City, UT, United States

25. Tomlinson $R$ (2005). Thinking about GIS: geographic information system planning for managers, Redlands, CA: ESRI Press.

26. URISA Journal (2015). Special issue on Return on investment in GIS, 27(1): 13-46. Des Plaines, IL: Urban and Regional Information Systems Association (URISA).

27. Wang, R (1908) "A product perspective on total data quality management", Communications of the ACM 41(2): 58-65.

28. Wysocki, R.K., Beck, R. Jr. and Crane, D.B. (2003) Effective project management, 3rd ed., New York, NY: John Wiley \& Sons. 